\title{
The Exploitation of Affect and Graduation in English Advertisements on Kids' Meals and Its Influence on the Process of Character Building
}

\author{
Stella Duce Jingga ${ }^{1}$, Djatmika ${ }^{2}$, Riyadi Santosa ${ }^{3}$, Dyah Ayu Nila Khrisna ${ }^{4}$ \\ \{stelladj@student.uns.ac.id ${ }^{1}$, djatmika@ staff.uns.ac.id ${ }^{2}$, riyadisantosa@ staff.uns.ac.id ${ }^{3}$, \\ dahayu@staff.uns.ac.id $\left.{ }^{4}\right\}$ \\ English Department, Faculty of Cultural Sciences, Universitas Sebelas Maret \\ Jl. Ir. Sutami 36 A, Surakarta, Indonesia 57126 1,2,3,4
}

\begin{abstract}
This paper talks about the roles of Affect and Graduation as parts of the appraisal system in English advertisements on kids' meals to the process of character building. Various English advertisements on kids' meals were collected from youtube to analyze the way affect and graduation are exploited in the promoting texts, and then to see whether the exploitation influences the process of character building. The results show that many selected emotive words representing positive feelings for the meals being promoted. These are supported by the graduation for the selected words, while several others have negative impressions towards the foods. The positive emotive words tend to be beneficial as being models for children in their point of view to the foods, while the negative ones should be revised to have a positive contribution to the process of character building.
\end{abstract}

Keywords: affect, graduation, kids' meals, character building

\section{Introduction}

Food commercials' exposure influences children to actively ask their parents to buy and consume food products since they are vulnerable enough to counter the structured advertisement using understandable dictions and great visual which stimulates their minds to elaborate that the product meets their expectations on their dream food[1]. This paper will explore sweet and cereal advertisements like Kinder Joy, Kinder Chocolate, Milka, Hershey's, Annie's Homegrown, and Kellogg's Australia that are mainly aimed at children. However, kids' meal advertisement is believed to shape certain characteristics of children as a consumer. The process of character building that the producer of the food itself and the marketing strategist delivered to children use linguistic construction that can be analyzed through affect and graduation approach of Systemic Functional Linguistics into descriptive qualitative research. Moreover, this research will describe how the use of affect and graduation on the consumer of food products advertised that is children, intentionally on the character building. While prior research mostly engaged appraisal with news[2-4], academic writing[5-6], and personal statements on online social media[7], the study about appraisal theory in English advertisement particularly on kids' meal has not been elaborated and later it becomes the research gap to conduct the research. 


\section{Theoretical Framework}

\subsection{Advertisement}

To deliver the value of a product or service that meet consumer's desires and needs, online media such as YouTube, Instagram, Facebook, or website, and offline media like newspaper, radio, magazine, or television help producers broaden their targeted consumer including children[9]. Along with Hanh and Kovashka, video advertising results in skyrocketing demand for certain products than any traditional media through a video using contexts and techniques such as message repetition, branded characters, attention-getting production features, and animation has more potential large spreads coverage area[10]. Moreover, advertising becomes immensely powerful as the context can build the right emotional atmosphere that engaged with the targeted consumer[11].

\subsection{Appraisal System}

Appraisal explores the way how language is integrated as an interpersonal meaning addressing person, thing, or behavior that later becomes a system of evaluation[12]. In a big line, the evaluation comes up with positive or negative value about targeted person, thing, or behavior resulted in certain marks that differ from others. The three values building appraisal are attitudes (emotion), graduation (measurement tool), and engagement as the following chart shows:

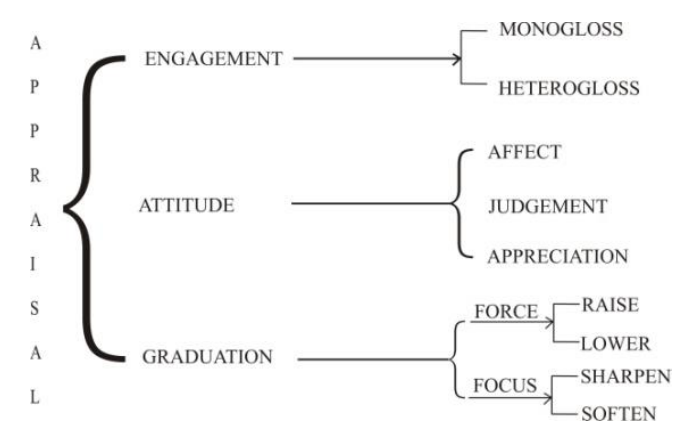

Figure 1. Appraisal Concept[12]

\subsubsection{Attitude}

Attitude is a meaning system exploiting evaluation resources into three domains: emotion, ethics, and aesthetics into affect, judgement, and appreciation[12]. However, appraisal is defined as "evaluation of attitudes types that are negotiated in the texts, how strong are the emotion involved, and how the core values are sourced to the audience.". In 2005, appraisal comes up with established, amplified, and targeted evaluation or person, thing, or behavior that are integrated as a system. It mainly discusses feelings on how good and bad vibes elaborated directly or impliedly throughout the attitudinal lexis that later categorized as an affect. Judgement is about ethical behavior. Last, aesthetics talks about the understanding of evaluation towards person, thing, and behavior by analyzing appreciation.

\subsubsection{Affect}

Affect is the expression of emotion that can be categorized into positive and negative. However, infants carry out emotion since they were born. Even more, they cry and laugh to communicate with their parents as their first language acquisition process. Emotions are instinctive and natural. Whenever the baby feels comfortable, they laugh. On the contrary, 
they will cry as soon as they feel uncomfortable. Thus, if the baby laughs it means the affection is positive[13]. Positive means the emotion built makes the audience feel comfortable, good, loved, happy, or cheerful, while negative means vice versa[12].

\subsubsection{Graduation}

Graduation is a measurement tool on how sharp or soft attitudinal lexis are expressed[12]. It can be seen through the high, medium, or low level of gradation of intensifiers, quantifications, sharpening, or softening used on the amplification clause as a level of distinctions between the words. Furthermore, graduation is split into two types: force and focus. Force deals with the scale of intensity build through the quality, process, and modality. On the other hand, focus does not discuss scaling intensity but how the intensity is sharpened or soften so the value of the attitude delivered to construct the meaning.

\section{Methods}

Data in the forms of verbal expressions representing affect and graduation related to food products were collected from kids' meal advertisements uploaded on YouTube from September 15, 2015, to October 14, 2019. The collected data were then analyzed to see how the expressions represent the advertisers' affect toward the commodities being promoted and how the expressions influence the kids' character building.

\section{Finding and Discussion}

The study elaborates kids' meal advertisements such as sweets and cereals: “Kinder Joy TV Commercial South East Asia 2015"; Kinder Chocolate; Hershey's Milk Chocolate Bars; Milka; Annie's Mission of Annie's Homegrown; and “\#PerfectBowl Family Breakfast $60 \mathrm{sec}$ | Kellogg's Australia” into 12 realizations of positive affect: 4 inclinations lexis; 4 happiness lexis, 3 security lexis, 1 satisfaction lexis and also 11 realizations of graduation: 7 force expression; and 4 softening lexis that are shown as follows:

Table 1.Realization of Positive Affect

\begin{tabular}{ll}
\hline Types of Affect & Realization \\
\hline Dis/inclination & 1. I love seeing my children happy. \\
& 2. And I only give them what I trust. \\
& 3. I've wanted to leave the planet better for my children \& their \\
& children \\
& 4. This is my perfect bowl. That's yours? \\
Un/happiness & 1. Also, exciting toys for boys and girls that stimulate their minds. \\
& 2. A yummy milky center, and a taste that kid loves. \\
& 3. I like guy with Hershey's Bar. \\
& 4. I thought well I could give somebody a Hershey's bar to put a \\
In/security & 1. Ande on their face. \\
& 2. I'm Carla Five them what I trust. \\
3. That's why I'm committed to help Annie's find the best \& most \\
1. Helicious organic \& regenerative ingredients.
\end{tabular}


As illustrated by the mental processes shown in the attitudinal lexis 'love', 'like', and 'trust' are the way sensers express their feeling of positive affection towards the phenomenon exploited in Kinder Joy advertisement. The commercial carried out linguistic construction of affect particularly the happiness expression shown in mother feeling's towards her happy kids in the beginning scene of the advertisement as a portrayal of a mother who trusted a combination of chocolate and wafer balls, Kinder Joy, to light up her children's happiness. However, mental behavioral processes were seen in inclination and security surge of behavior such as 'give', 'wanted', and 'committed' capture the value of trust and confidence. Whilst, in the quality disposition in the form of attributive or epithet like thrilled, heart-warming, sweeter, nice, exciting, proud, and generous, are the exploitations of positive affect performed in Table 1 that may help children to develop their mental characteristics such as emotion, affection, respect, and empathy as children watch and hear those stimulants that later work on their unconsciousness resulting in the positive character of children as they imitate the commercial and consume the product[14]. There is no negative affect found throughout the transcript of advertisement videos that strengthens the positive vibes.

Table 2.Realization of Graduation

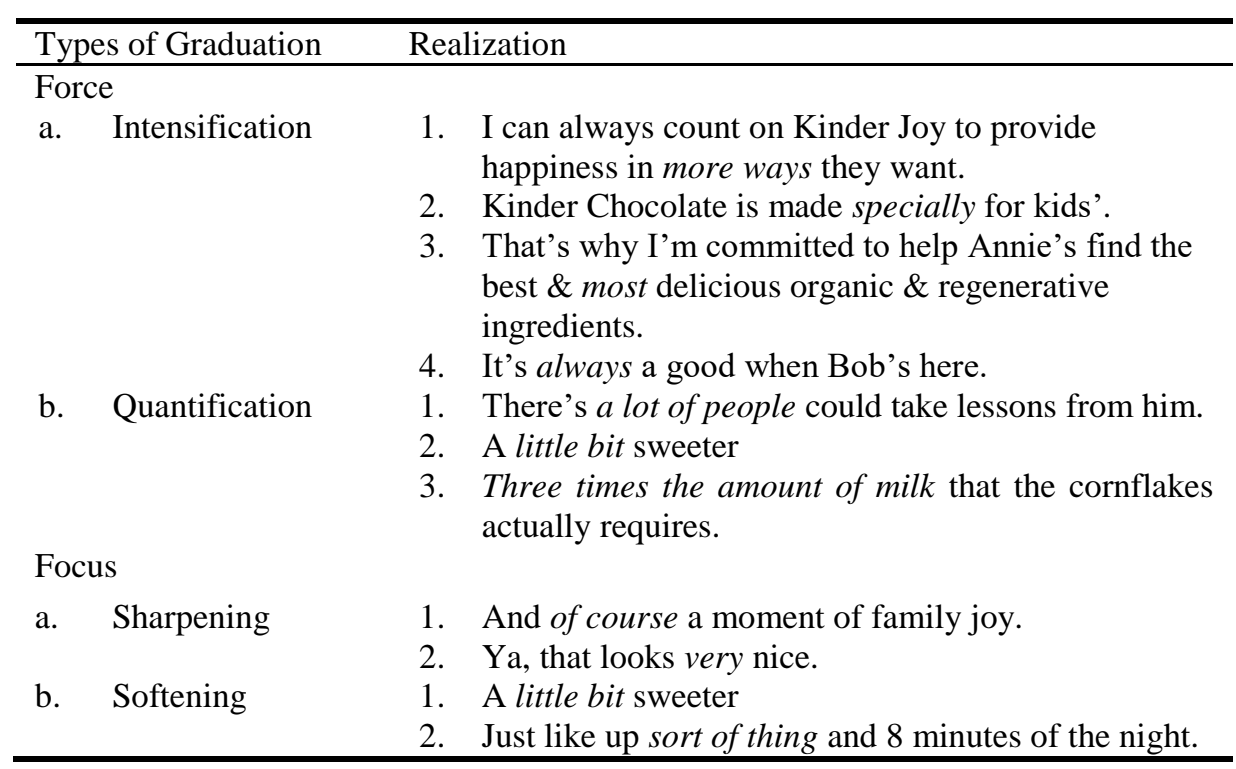

However, moral developments transmitted by the advertisement value are also supported by graduation used throughout the context by emphasizing intensifiers and quantifications carrying out force and focus that may sharpen or soften the attitudinal lexis exploiting positive affects as revealed by the exploitations of 'more', 'always', 'of course', 'specially', 'most', 'little bit', 'sort of', 'very', and 'a lot of'. In the intensification realization 1, 'more ways' strengthen the emotional meaning of the mental behavioral process 'they want'. Next, on the second realization the use of graduational lexis, 'specially' emphasizes the phenomenon 'for kids'. The phenomenon 'delicious organic and regenerative ingredients' also climb the peak of comparison order since the intensifier 'most' is placed right before the phenomenon. Also, the modal word 'always' placed as an isolation form where it stands alone to strengthen the good feeling when Bob, the old man gave everyone he met a Hershey's Chocolate Bar, is 
around. Furthermore, the realizations of positive affect in the form of inclination, happiness, security, and satisfaction surge of behavior are responsible for the character-building process of children as its consumer. As long as the realizations containing positive emotional affect lexis is performed and elaborated along with the contexts of advertisement, it can help parents and children choose the right food and grow into a strong and good character. Later, as children character developed, children will appreciate and love the food they consume, also have a better empathy towards others.

\section{Conclusion}

The linguistic phenomenon that is attitudinal lexis scattered throughout the promotional videos analyzed in the affect and graduation is believed to build a good character of children as the consumer even though the ingredients are not so good for children to consume. In particular, graduations found throughout the advertisements support the participants and phenomenons that carried out the exploitation of affects, especially the positive one. Furthermore, the language used that carries out emotive lexis in a simple understandable form of advertisement words can stimulate children to do so, both good and bad behavior or ideology that the food company would implement to children through the commercials. In the future study, the researcher may emphasize and elaborate more by carrying out children as the subject of the research and a discourse completion task containing character-building tests.

\section{References}

[1] Harris JL, Kalnova SS. Food and beverage tv advertising to young children: measuring exposure and potential impact. Appetite. 2018; 49-55.

[2] Khoo CSG, Nourbakhsh A, Na JC. Sentiment analysis of online news text: a case study of appraisal theory. Online Information Review. 2012; 36(6).

[3] Chalimah, Djatmika, Santosa R, Wiratno T. Evaluating attitudes in news text: appraisal in critical discourse study. Advances in Social Science, Education and Humanities Research. 2018; 166.

[4] Yopi T, Alimin FG, Samad I, Weda S. Prabowo's anger during 212 reunion: an appraisal system of cnn indonesia news text. International Journal of Linguistics and Literature.. 2019; 5(1):217-224.

[5] Mori M. Using the appraisal framework to analyze source use in essays: a case study of engagement and dialogism in two undergraduate students' writing. Functional Linguistics. 2017; 4(11). Available fromhttp://doi.org/10.1186/s40554-017-0046-4/

[6] Geng Y, Wharton S. How do thesis writers evaluate their own and other's findings? an appraisal analysis and a pedagogical intervention. English for Specific Purposes. 2019; 56:3-17.

[7] Ross AS, Caldwell D. 'Going negative': an appraisal analysis of analysis of the rhetoric of donald trump on twitter. Language \& Communication. 2020; 70:13-27.

[8] Calvert SL. Children as consumers: advertising and marketing. The Future of Children. 2008;18(1). Available fromhttp://doi.org/10.1353/foc.0.0001/

[9] Hanh J, Kovashka, A. Measuring effectiveness of video advertisements. Journal Arxiv. 2019.

[10] Mizerski R, White JD. Understanding and using emotions in advertising. Journal of Consumer Marketing. 1986;3)4):57-69. Available from http://doi.org/10.1108/eb008180/

[11] Martin JR, White PR. Language of evaluation-appraisal in english. London: PalgraveMacmillan; 2005.

[12] Choliz M, Fernandez-Abascal EG, Martinez-Sanchez F. Infant crying: pattern of weeping, recognition of emotion and affective reactions in observers. The Spanish Journal of Psychology. 2012;15(3):978-88. Available from http://doi.org/10.5209/rev_SJOP.2012.v15.n3.39389/

[13] Kim S, Choo I, Kaufman J. The development and evaluation of the effect of creative problemsolving program on young children's creativity and character. Thinking Skills and Creativity. 2019;33. Available from http://doi.org/10.1016/j.tsc.2019.100590/ 